\title{
Operando Raman analysis of electrolyte changes in Li-ion batteries with hollow-core optical fibre sensors
}

\section{Ermanno Miele}

University of Cambridge

\section{Wesley Dose}

University of Cambridge

llya Manyakin

University of Cambridge

\section{Michael Frosz}

Max Planck Institute for the Science of Light https://orcid.org/0000-0002-8857-0029

\section{Michael De Volder}

University of Cambridge https://orcid.org/0000-0003-1955-2270

\section{Clare Grey}

University of Cambridge https://orcid.org/0000-0001-5572-192X

Jeremy Baumberg

University of Cambridge https://orcid.org/0000-0002-9606-9488

Tijmen Euser ( $\sim$ te287@cam.ac.uk)

University of Cambridge https://orcid.org/0000-0002-8305-9598

\section{Article}

Keywords: Degradation and Failure Mechanisms, High Energy Density Energy Storage Materials, in-situ Tracking of Electrolyte Chemistry, Carbonate Solvents and Electrolyte Additives, Lithium-ion Solvation Dynamics

Posted Date: June 2nd, 2021

DOl: https://doi.org/10.21203/rs.3.rs-531818/v1

License: (c) (i) This work is licensed under a Creative Commons Attribution 4.0 International License. Read Full License

Version of Record: A version of this preprint was published at Nature Communications on March 28th, 2022. See the published version at https://doi.org/10.1038/s41467-022-29330-4. 



\section{Operando Raman analysis of electrolyte changes in Li-ion batteries with hollow-core optical fibre sensors}

Ermanno Miele, ${ }^{1,2,5}$ Wesley M. Dose, ${ }^{2,3,5}$ Ilya Manyakin, ${ }^{1}$ Michael H. Frosz, ${ }^{4}$ Michael F.L. De Volder, ${ }^{3,5}$

Clare P. Grey, ${ }^{2,5^{*}}$ Jeremy J. Baumberg, ${ }^{1,5^{*}}$ and Tijmen G. Euser ${ }^{1,5^{*}}$

${ }^{1}$ Nanophotonics Centre, Department of Physics, Cavendish Laboratory, University of Cambridge, CB3 OHE, Cambridge, United Kingdom

${ }^{2}$ Department of Chemistry, University of Cambridge, Lensfield Road, CB2 1EW, Cambridge, UK

${ }^{3}$ Institute for Manufacturing, Department of Engineering, University of Cambridge, 17 Charles Babbage Road, CB3 OFS, Cambridge, UK

${ }^{4}$ Max Planck Institute for the Science of Light, Staudtstr. 2, 91058, Erlangen, Germany

${ }^{5}$ The Faraday Institution, Quad One, Harwell Science and Innovation Campus, Didcot OX11 ORA, Oxford, UK

*e-mail: te287@cam.ac.uk, jib12@cam.ac.uk, cpg27@cam.ac.uk

\section{Abstract}

New methods are urgently required to identify degradation and failure mechanisms in high energy density energy storage materials such as Ni-rich $\mathrm{LiNi}_{0.8} \mathrm{Mn}_{0.1} \mathrm{Co}_{0.1} \mathrm{O}_{2}$ cathodes (NMC811) for Li-ion batteries. Understanding and ultimately avoiding these mechanisms requires in-situ tracking of the complex electrochemical processes that occur in different parts of battery cells. Here we demonstrate a new operando spectroscopy method that enables the tracking of electrolyte chemistry, applied here for high energy density Li-ion batteries with a NMC811 cathode, during electrochemical cycling. This is achieved by embedding a novel hollow-core optical fibre probe inside the battery to monitor the evolution of electrolyte species by background-free Raman spectroscopy. Our data reveals changes in the ratio of carbonate solvents and electrolyte additives as a function of the cell voltage, as well as changes in the lithium-ion solvation dynamics. This advanced operando methodology delivers a new way to study battery degradation mechanisms, and the understanding it develops should contribute to extending the lifetime of next-generation batteries. 


\section{Introduction}

The development of longer-lasting batteries requires that the degradation mechanisms that cause Li-ion battery (LIB) failures are better understood. The performance loss is particularly high in electrical-vehicle batteries with next-generation high energy cathodes, such as $\mathrm{Ni-rich} \mathrm{LiNi}_{x} \mathrm{Mn}_{y} \mathrm{Co}_{(1-x-y)} \mathrm{O}_{2}(\mathrm{NMC}, \mathrm{x}>0.6),{ }^{1}$ where a wide range of damaging mechanisms have been proposed, involving different cell materials and coupled reaction processes. ${ }^{2-11}$ Suggested mechanisms include inter- and intra-granular cracking of cathodes $^{2,3}$ leading to capacity loss and to dissolution, and release of transition metal ions, affecting the formation and stability of the anode Solid Electrolyte Interphase (SEI) layer that is essential for battery operation. ${ }^{4,12-15}$ Additional destructive processes include lattice oxygen release at the electrodeelectrolyte interface (EEI) of the NMC cathode. ${ }^{10,11}$ The onset potential for this is lower for NMCs with higher $\mathrm{Ni}$ content, ${ }^{5,6}$ where oxygen loss results in a structural transformation of the surface. ${ }^{7,16,17}$ Oxygen release has also been linked to the observed (electro)chemical degradation of the $\mathrm{Li}^{+}$-solvated carbonate solvents that comprise the electrolyte, such as Ethylene Carbonate (EC) $\cdot{ }^{5,18-20}$ Additives such as Vinylene Carbonate (VC) are often added to improve SEl stability but their role in cathode processes is less clear. ${ }^{8,9,21}$ A particularly sensitive probe of such coupled mechanisms is the electrolyte, because it contains a range of reaction by-products, the study of which should thus lead to an improved understanding of the complex interactions that cause the overall cell degradation.

Unfortunately, there is currently a lack of experimental techniques for operando monitoring of the electrolyte composition and structure within full-cell batteries. The ideal sensor would (i) not perturb the device operation, (ii) be non-destructive, (iii) not compromise safety, (iv) work during battery operation, and ( $v$ ) be easily combined with other cell components without affecting the operation and lifetime of the battery. ${ }^{22}$ Suitable sensing probes include the molecular vibrational spectroscopies, FT-IR and Raman, ${ }^{23}$ which have recently gained popularity in battery science due to their ability to provide a safe, fast, and 
label-free analysis of the chemical composition and evolution of different battery components. Recent examples are the in-situ FT-IR analysis of the oxidation of EC at the $\mathrm{LiNi}_{0.8} \mathrm{Mn}_{0.1} \mathrm{Co}_{0.1} \mathrm{O}_{2}(\mathrm{NMC} 811)$ interface, ${ }^{9}$ and in-situ Raman studies on graphite electrodes. ${ }^{24,25}$

In the above studies, experiments are typically carried out in half-cell configurations with optical access windows, and processes are investigated at either the negative or positive EEl. A drawback of half-cell geometries is that they result in different (electro)chemical behaviour compared to that in full-cells. In addition, the electrode-surface to electrolyte-volume ratio in such cells is often much smaller than in commercial cells, and electrolyte measurements in such systems do not necessarily capture the complex cross-talk and interplay between cathode, anode, and electrolyte processes within batteries under real working conditions, ${ }^{26}$ or allow commercial cells to be studied. There is therefore an urgent need to develop non-perturbing optical detection methods for full-cell batteries, to enable studies of the electrolyte's role in more complex degradation processes and failure mechanisms, ultimately leading to real time electrolyte monitoring in commercial cells.

Fibre-optic devices are emerging as useful non-perturbative sensors within batteries due to their small footprint, non-conductance, and chemical stability. For example, fibre Bragg sensors can be used to monitor volume- and temperature changes in batteries during cycling. ${ }^{27,28}$ More recently, carefully processed silica fibre probes $^{29}$ were used to monitor electrolyte composition near the tip of a fibre by Raman spectroscopy. ${ }^{30}$ This work was based on solid-glass optical fibres, which face several limitations: first, the short interaction length between the pump light and sample results in relatively weak Raman signals. In addition, the pump light is delivered through a solid silica fibre, resulting in a significant Raman background that limits the detection sensitivity. 
Hollow-core optical fibres (HC-fibres), on the other hand, offer an excellent way to remove the silica Raman contribution and to enhance the light-matter interaction length. These HC-fibres comprise a central core channel surrounded by a glass microstructure designed to support low-loss light guidance within a specific wavelength range. Early designs relied on photonic bandgap and interference effects in periodic cladding structures. ${ }^{31,32} \mathrm{HC}$-fibres have since found application in gas-based non-linear optics ${ }^{33}$ and as liquid-filled optofluidic microreactors for a range of photochemical and catalytic reactions. ${ }^{34}$ In Raman spectroscopy, HC-fibres have been exploited in the flexible and background-free delivery of pump light to a sample, ${ }^{35-37}$ and for background-free Raman sensing in aqueous samples in a hollow-core photonic bandgap fibre. ${ }^{38}$ Recently, it has been shown that simplified HC-fibre structures, consisting of a single ring of capillaries surrounding a central waveguide core (see Fig. 1), can also provide excellent lowloss guidance. ${ }^{39-43} \mathrm{~A}$ major advantage of these fibres is their simplified fabrication process and less complex cladding structure that facilitates the infiltration of liquid samples.

Here we use simplified hollow-core fibre probes to overcome significant challenges for operando battery spectroscopy methods. A sub- $\mu$ L electrolyte sample from a working NMC811-graphite LIB is repeatedly sampled into the fibre core, and its chemical composition analysed by background-free Raman spectroscopy. The sample is infused back into the battery, and the measurement is repeated continuously, resulting in a real-time trace of the electrolyte chemistry during battery cycling.

Multiple studies have found that the solvent EC and additive VC are involved in crucial reaction pathways at the surface of the SEI at graphite anodes and in the bulk electrolyte..$^{9,20,21,44}$ The key aim of this proofof-principle operando Raman study is therefore to monitor the electrolyte chemistry directly during the formation of the SEI layer during the first electrochemical cycle (formation cycle) of an NMC-graphite full cell. ${ }^{45,46}$ 
a

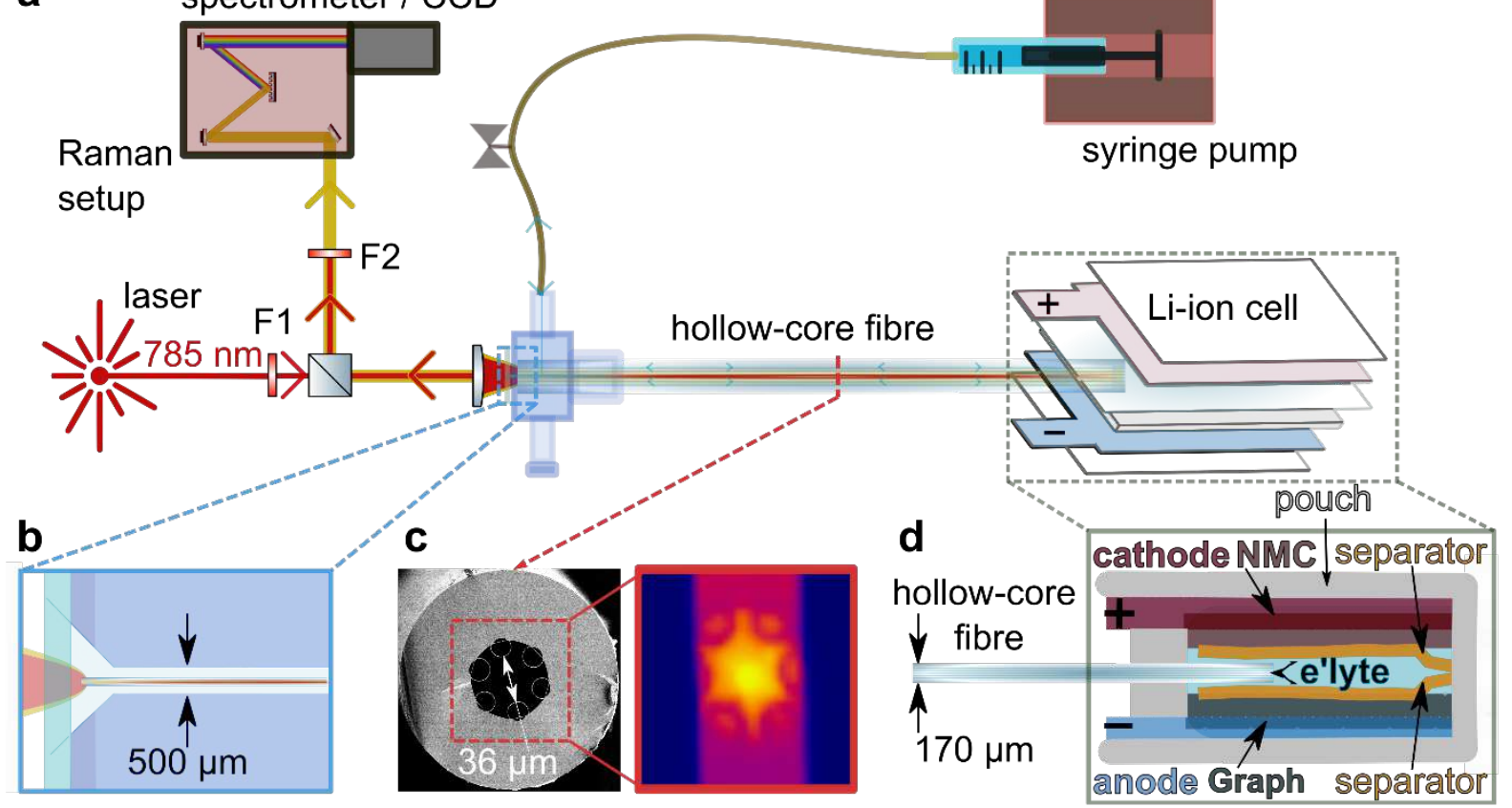

Fig. 1 | Hollow-core fibre-coupled Raman analysis of a Li-ion battery full cell. a,b, Continuous wave laser light (785 $\mathrm{nm}$ ) is filtered and launched into the core of a single-ring HC-fibre. The proximate fibre facet is embedded in a microfluidic chamber with a sapphire window (b) and connected to a syringe pump for on-demand sampling / infusion, while the distal fibre facet is embedded in the pouch cell under study. The backscattered Raman signal generated within the HC-fibre is reflected off a 50:50 beam-splitter, filtered and analysed by a spectrometer. F1, bandpass filter; F2, notch filter. c, SEM image of the hollow-core fibre with an outer diameter of $174 \mu \mathrm{m}$ and a core diameter of $36 \mu \mathrm{m}$ (measured between the inner capillaries (see Supplementary Fig. 1). The righthand image shows the Raman signal detected by the spectrometer CCD camera. $\mathbf{d}$, Schematic indicating the electrodes, separator and fibre probe arrangements within the pouch cell (not to scale - for details, see Supplementary Fig. 4).

\section{Results}

Hollow-core fibre Raman sensor. In the Raman setup (Fig. 1a), the proximate end of the hollow-core fibre is embedded in a custom-made ultralow-dead-volume microfluidic cell that allows optical and fluidic access to the fibre (Fig. 1b). The distal end of the fibre is fitted and sealed in between the electrodes of a pouch cell. Two layers of monolayer PE polymer separator (MTI) were used to avoid direct contact between the fibre and the electrodes (Fig. 1d). The simplified hollow-core fibre (Fig. 1c) was designed 
optimising the light guidance in the wavelength range of the Raman pump light and signal ${ }^{39-41,47}$ when filled with electrolyte (see Methods and Supplementary Figs. 1-2). The $36 \mu \mathrm{m}$ wide core region of the optofluidic fibre acts as both a waveguide and microfluidic channel, with a low internal volume of $30 \mathrm{~nL}$ per $\mathrm{cm}$ length. ${ }^{48}$ An automated syringe pump is used to sample and infuse electrolyte from the pouch cell on demand.

A Raman pump laser (785 nm continuous wave, Fig. 1a) is launched into a waveguide mode of the electrolyte-filled fibre core using an underfilled 10x 0.3 NA microscope objective. Raman signals are generated along the length of the fibre, and a portion is captured in backward-propagating fibre modes and guided back to the proximate fibre facet. The CCD image of the generated Raman light (right-hand image in Fig. 1c) shows that most of the Raman light is generated and guided within the hollow fibre core. After each optical measurement, the electrolyte sample is injected back into the pouch cell. In the current configuration, a single sampling interval takes $22 \mathrm{~min}$ ca. $4 \%$ of the full discharging time and is continuously repeated to monitor the electrolyte chemistry over extended time periods (a typical chargedischarge formation cycle takes more than 10 hours, but is not limited by the fibre measurement).

On-line Raman collection in hollow-core fibre. The dynamic exchange and Raman spectroscopy within the fibre core were first tested ex-situ without the pouch cell for a range of electrolyte components and typical solvents (Fig. 2). End facet images and spectrally dispersed fibre images were collected by the spectrometer CCD (Fig. 2a). Initially the fibre was filled with isopropyl alcohol (IPA), whose Raman spectrum is shown in Figs. 2b-c. To exchange samples, syringe inputs were swapped and the pump of a new component set to flow rate at $5 \mu \mathrm{L} / \min (0.083 \mu \mathrm{L} / \mathrm{s})$ to infiltrate the fibre core. 


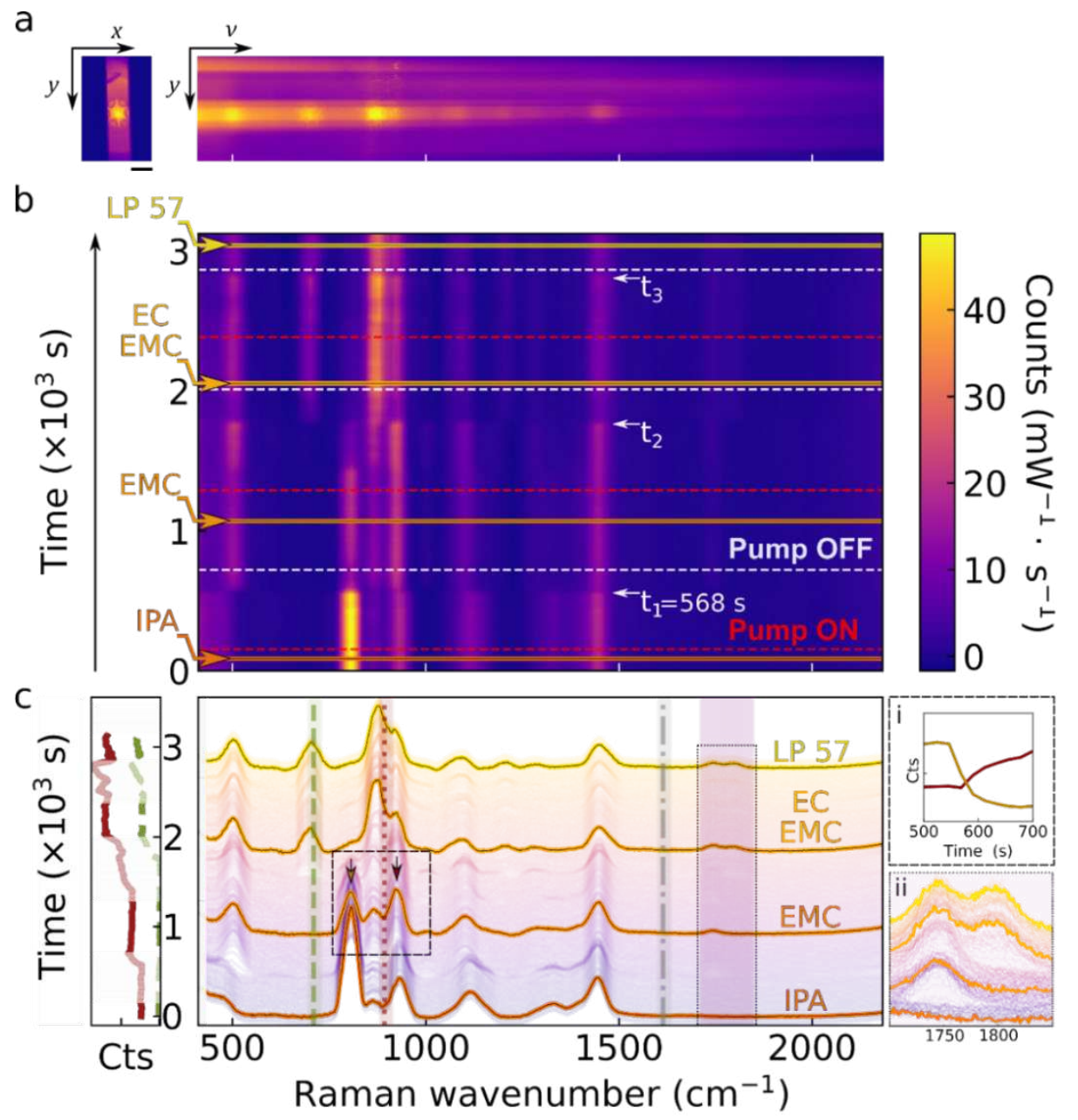

Fig. 2 | Online Raman measurements in a hollow-core fibre. a, Raman light emerging from the fibre facet (left, image scalebar is $50 \mu \mathrm{m}$ ) with spectrally dispersed image (right). $\mathbf{b}$, Raman spectra tracked during sequential sample infiltration. Red dashed lines indicate when the pump is switched on; $t_{1-3}$ indicate the times at which the sample fluid reaches the fibre core. Dashed white lines indicate the times where the pump is switched off, and is followed by a switch of the sample syringe. Solid horizontal lines indicate times at which the spectra shown in (c) were taken. c, Obtained spectra of the different solvent mixtures, highlighting Raman bands relevant to battery chemistry: ethylene carbonate breathing mode at $893 \mathrm{~cm}^{-1}$ (dark red dotted line), $\mathrm{PF}_{6}$ anion mode at $740 \mathrm{~cm}^{-1}$ (green dashed line), and vinylene carbonate $C=C$ band centred at $1628 \mathrm{~cm}^{-1}$ (not present in these solutions and spectra). The shaded area indicates EC and EMC bands at $1700-1850 \mathrm{~cm}^{-1}$ relevant to lithium solvation mechanisms (see Fig. 4), rescaled also in inset ii. Inset i demonstrates the sample exchange time as monitored by the Raman intensity of the IPA (819 $\mathrm{cm}^{-}$ $\left.{ }^{1}\right)$ and EMC skeleton $\left(\sim 900 \mathrm{~cm}^{-1}\right)$ modes (arrows in c). 
Spectra were continuously recorded with a $20 \mathrm{sec}$ integration time per spectrum throughout the experiment. Samples sequentially infiltrated into the fibre here are: IPA, ethyl methyl carbonate (EMC), a 3:7 mixture of ethylene carbonate (EC) and EMC, and the commonly used electrolyte mixture LP57 (EC:EMC 3:7 (v) + 1.0 M LiPF6). During the collection of the Raman spectra an optimal trade-off was made between spectral range, resolution, and signal strength (Fig. 2b).

Relatively broadband Raman spectra (Fig. 2c) are taken after the signal stabilized and the syringe pump switched off. The fluidic stabilisation time of the system after sample exchange is currently $\sim 400 \mathrm{sec}$ (corresponding to a flow volume of $\sim 33 \mu \mathrm{L}$, Fig. $2 \mathrm{c}$ ). The spectra display cleared Raman signatures of the various electrolyte components: Firstly, the dashed green line corresponds to the spectral position of the $\mathrm{PF}_{6}{ }^{-}$anion Raman band at $740 \mathrm{~cm}^{-1},{ }^{49}$ which partially overlaps the EC-skeletal mode at $\sim 720 \mathrm{~cm}^{-1} .{ }^{50}$ The ability to detect $\mathrm{PF}_{6}{ }^{-}$is useful since its decomposition is a proposed degradation mechanism occurring at the surface of high covalency cathodes such as NMC $811,{ }^{8}$ and it reacts readily with the water that can be generated in electrolyte decomposition reactions. Secondly, the EC breathing mode is seen at $893 \mathrm{~cm}^{-1}$ (dotted red line), which is connected to the ring structural integrity of the molecule. Finally, the shaded (broad purple) band between $1700-1850 \mathrm{~cm}^{-1}$ corresponds to Raman peaks of the carbonyl $(\mathrm{C}=0)$ bonds in $\mathrm{EMC}$ and $\mathrm{EC} / \mathrm{VC}^{51,52}$ and its spectral features are directly related to the lithium ion solvation dynamics (see Fig.4). ${ }^{50,53}$ Also marked are the expected positions of the (weak) spectral band at $1628 \mathrm{~cm}^{-1}$ (dotted grey line) due to $C=C$ vibrations of the additive $V C$ (explored below in Fig. 3). These data clearly demonstrate the ability to monitor a wide range of different electrolyte components. 
Voltage [V]

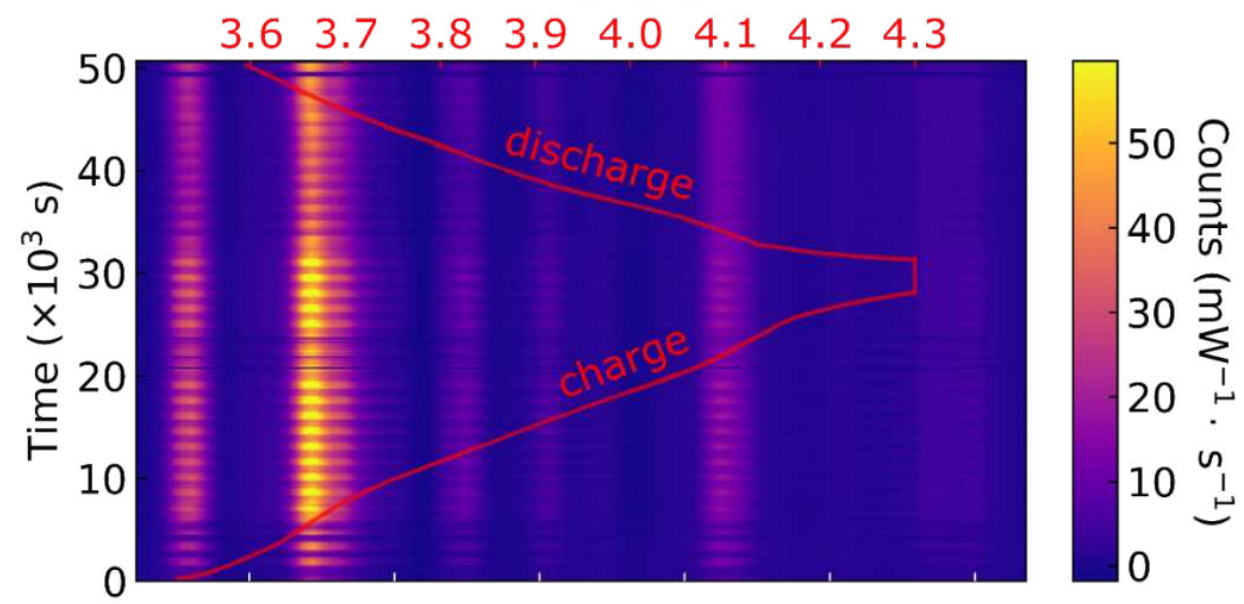

b

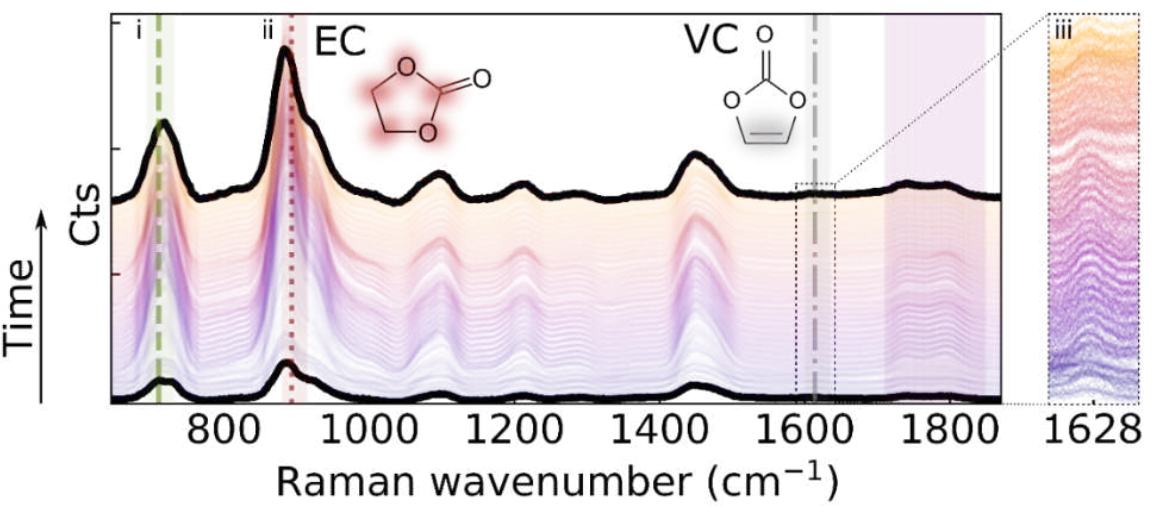

Fig. 3 | Battery electrolyte Raman spectral evolution during cycling. a, Operando Raman spectroscopy performed during the formation cycle of a $\mathrm{LiNi}_{0.8} \mathrm{Co}_{0.1} \mathrm{Mn}_{0.1} \mathrm{O}_{2}$ (NMC811) - graphite Li-ion pouch cell with an electrolyte comprising LP57 + 2 wt.\% VC. The cell was charged galvanostatically to $4.3 \mathrm{~V}$, potentiostatically held at $4.3 \mathrm{~V}$, and then discharged. During the cycle, electrolyte samples are extracted, Raman spectra acquired, and the electrolyte re-injected back into the separator compartment. b, Raman spectral evolution showing a range of Raman modes of battery electrolytes, particularly: (i) $\mathrm{PF}_{6}{ }^{-a n i o n}$, symmetric stretch (740 $\mathrm{cm}$ 1, green dashed line), (ii) EC, skeletal breathing mode ( $893 \mathrm{~cm}^{-1}$, dotted red line), (iii) VC, C=C (1628 $\mathrm{cm}^{-1}$, grey dash-dotted line, displayed in inset where the signal was multiplied by 4 , relative to that shown in (b)).

Operando Raman measurements in full cell batteries. To track the electrolyte chemistry operando in a $\mathrm{Li}$-ion battery, a hollow-core fibre is embedded in a pouch cell composed of a $\mathrm{LiNi}_{0.8} \mathrm{Co}_{0.1} \mathrm{Mn}_{0.1} \mathrm{O}_{2}(\mathrm{NMC} \mathrm{M11})$ cathode and a graphite anode. Each electrode is covered by a layer of polymer separator and the HC-fibre 
is placed in between the two separator layers to protect the electrode surfaces from mechanical damage by the fibre (Fig. 1d). The cell is sealed and filled with $100 \mu \mathrm{L}$ of LP57 with 2 wt.\% VC additive. Details of the cell components and their assembly are in Supplementary Figs. 3-4. Even though the HC-fibre creates a slight spacing between the two separators, the total electrode surface to electrolyte volume ratio $\left(\sim 12 \mathrm{~cm}^{2} / \mathrm{mL}\right)$ remains very close to that of pouch cells assembled routinely in academic research.

The cell is galvanostatically charged to $4.3 \mathrm{~V}$, followed by a potentiostatic hold for $1 \mathrm{~h}$ at $4.3 \mathrm{~V}$, and a final discharge to $3.5 \mathrm{~V}$, with the cell cycled at rate of $\mathrm{C} / 10$. A $24 \mu \mathrm{L}$ volume microsample is extracted from the battery every 22 minutes, analysed by in-fibre Raman spectroscopy, and reinjected into the pouch cell. The time resolution required to monitor electrode processes can be estimated from the diffusion time $t_{d}$ of EC molecules across the cell. ${ }^{44}$ Assuming a polymer separator tortuosity of 2.5 and a liquid diffusion coefficient of $10^{-6} \mathrm{~cm}^{2} / \mathrm{s}^{44}$ this results in a diffusion time $t_{d}=445 \mathrm{~s}(\sim 7 \mathrm{~min})$ for our cell geometry. A broad spectral window $\left(640-2340 \mathrm{~cm}^{-1}\right)$ is chosen in order to simultaneously track a range of chemical species.

The evolution of the Raman spectra was measured as a function of the cell voltage (red curve) during the first electrochemical cycle, during which many chemical changes due to EEI formation are expected (Fig 3a). Clear signatures were observed of the spectral lines for $\mathrm{PF}_{6}^{-}$, the $\mathrm{EC}$ breathing mode, and the carbonyl (C=O) bonds in EMC and EC/VC, as identified in Fig $\mathbf{2 b}$. In addition, a (weak) C=C Raman band at $\sim 1628$ $\mathrm{cm}^{-1}$ (grey dash-dotted line) that is specific to the VC additive is detected (its variations will be discussed in more detail in Fig. 5b). The collected full Raman spectra throughout the cycle allow for a detailed analysis of the electrolyte components and their interactions. 


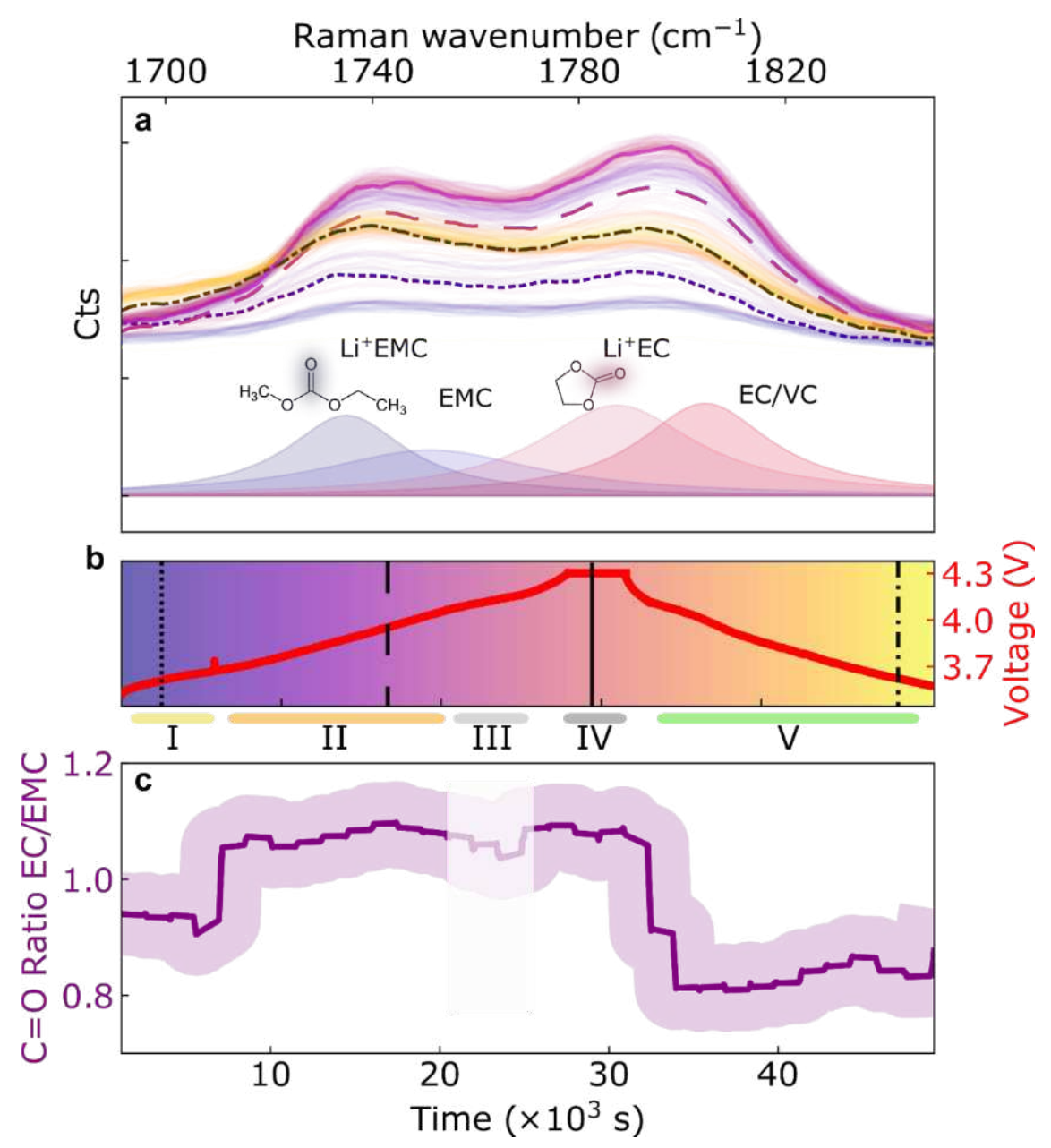

Fig. 4 | Monitoring $\mathrm{Li}^{+}$solvation to the different solvent carbonyl groups. a,b, Evolution of the carbonyl group (C=O) Raman bands during the formation cycle. Dashed and solid curves are spectra taken at times highlighted in (b). The deconvolution based on the solid purple line in (a) resolves peaks corresponding to the $\mathrm{C}=0$ stretch bands for unsolvated $\mathrm{Li}^{+}\left(\right.$dark blue, $\sim 1750 \mathrm{~cm}^{-1}$, for EMC and dark red, $\sim 1805 \mathrm{~cm}^{-1}$, for EC) and solvated $\mathrm{Li}^{+}$(light blue, $1735 \mathrm{~cm}^{-1}$, for Li ${ }^{+} \mathrm{EMC}$ and dark red, $\sim 1787 \mathrm{~cm}^{-1}$, for Li+ $\mathrm{EC}$ ). c, $\mathrm{Li}^{+}$-solvation dynamics $\left(\mathrm{Li}^{+}-\mathrm{O}=\mathrm{C}\right.$ tracked through the relative intensity of the experimental $\mathrm{EC} \mathrm{C}=\mathrm{O}\left(\sim 1790-1810 \mathrm{~cm}^{-1}\right)$ and $\mathrm{EMC}$ $\mathrm{C}=\mathrm{O}\left(\sim 1730-1750 \mathrm{~cm}^{-1}\right)$ bands. The shaded region indicates the $10 \%$ confidence interval. The complex interplay of lithium solvation dynamics with solvents (EC, EMC) and additive (VC) are segmented into different regimes (horizontal coloured lines IV) with different behaviour at each distinct state of charge.

Tracking lithium solvation dynamics. The solvation of lithium ions by carbonate solvents is an important process that regulates the interfacial chemistry at both the graphite and layered metal oxide EEI. ${ }^{54-56}$ In Raman, the band between $1700-1850 \mathrm{~cm}^{-1}$ is related to vibrations of the $\mathrm{C}=0$ group, the oxygen atoms of Page 11 of 29 
the carbonyl groups being largely responsible for solvating the lithium ions. ${ }^{57-61}$ The Raman bands in the spectral region observed at $1700-1850 \mathrm{~cm}^{-1}$ (Fig. 4) illustrate the evolution of cyclic and linear carbonate $\mathrm{C}=\mathrm{O}$ stretches during the formation cycle (Fig. $\mathbf{4 b}$ ). The overall intensity of the $\mathrm{EC} \mathrm{C}=\mathrm{O}$ band follows a similar trend to the EC breathing mode in Fig. $\mathbf{5}$.

Lithium salt concentration in the electrolyte and the interfacial chemistries at the electrode surfaces can change the solvation structure of carbonates solvents. ${ }^{9,57,62,63}$ To further calibrate our methodology, exsitu test measurements were carried out by extracting EC:EMC mixtures with different Li concentrations from a cuvette into a hollow-core fibre sensor. The resulting data show that the EC breathing-mode intensity doubles when changing the Li concentration from 0.5 to $1 \mathrm{M}$ (Supplementary Fig. 5) and that the EC $C=O$ band doubles its strength relative to $E M C C=O$ for the same $\mathrm{Li}^{+}$concentration change. This calibration enables us to relate the observed spectral changes of the two peaks centred at $\sim 1740$ and $\sim 1800 \mathrm{~cm}^{-1}$ in Fig. 4a to changes of the lithium solvation at the carbonate solvents. In particular, the evolution of the balance between solvated cyclic carbonate $\left(\mathrm{Li}^{+}-\mathrm{O}=\mathrm{C}, \mathrm{EC}\right)$ and solvated linear carbonate $\left(\mathrm{Li}^{+}-\mathrm{O}=\mathrm{C}, \mathrm{EMC}\right)$ can be investigated by tracking the ratio between the $\mathrm{EC} \mathrm{C}=\mathrm{O}\left(\sim 1800 \mathrm{~cm}^{-1}\right)$ and the EMC $\mathrm{C}=\mathrm{O}\left(\sim 1740 \mathrm{~cm}^{-1}\right)$ Raman mode intensities during a cycle (Fig. 4c).

To help analysing the observed dynamics, the electrochemical cycle is divided into five different regimes: initially (up to $3.75 \mathrm{~V}$ - region $\mathrm{I}$ ), the $\mathrm{EC} C=\mathrm{O}$ and $\mathrm{EMC} \mathrm{C}=\mathrm{O}$ bands maintain a constant and similar intensity. As the cell voltage continues to increase, both Raman bands increase in intensity (region II), with the increase for EC $\mathrm{C}=\mathrm{O}$ being significantly higher. During discharge, around $4.1 \mathrm{~V}$ (transition IV-V), there is a sudden decrease in both the $\mathrm{EC} C=\mathrm{O}$ and $\mathrm{EMC} \mathrm{C}=\mathrm{O}$ bands, with the strongest reduction observed for $\mathrm{EC}$ $\mathrm{C}=\mathrm{O}$. 

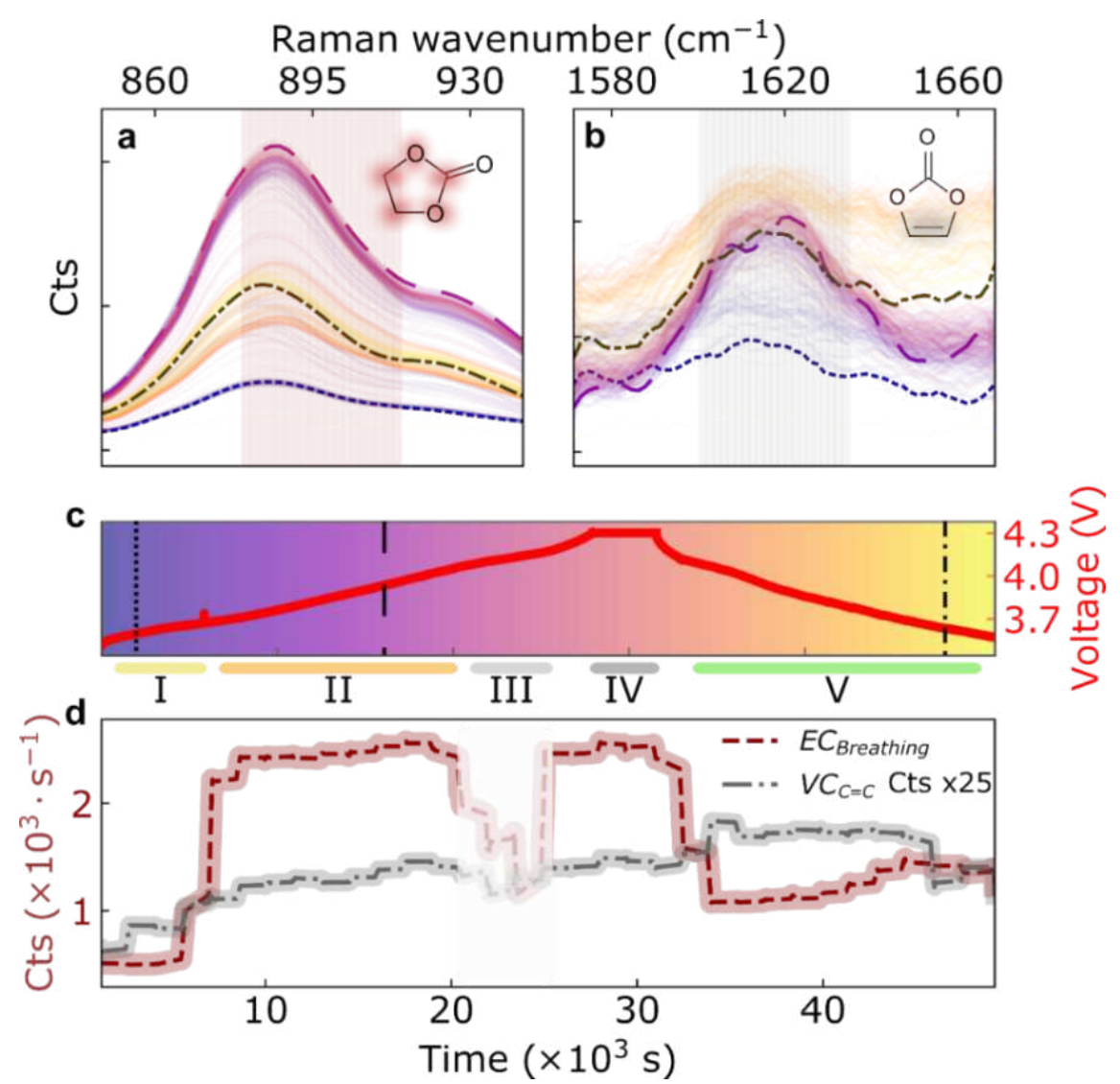

Fig. 5 | Monitoring Ethylene Carbonate (EC) solvent and Vinylene Carbonate (VC) additive concentrations. a,b, Evolution of Raman EC-breathing mode and VC C=C band during the formation cycle (normalized). Dashed curves are spectra taken at times highlighted in (c). c, Cell voltage during cycling, segmented into regions I-V. d, Time evolution of EC and VC Raman band intensities. The Raman signal intensity of the VC band in (b) was multiplied by 25 relative to that shown (a).

Monitoring Ethylene Carbonate and Vinylene Carbonate dynamics. To monitor the evolution of EC and VC concentrations during SEI formation, the EC breathing mode (Fig. 5a) and VC C=C band (Fig. 5b) are monitored during the formation cycle, and distinct changes in the EC intensity at different stages of the cycle are seen (Fig. 5a). At $3.75 \mathrm{~V}(\mathrm{t}=6,000 \mathrm{~s})$, the EC band intensity rapidly increases by a factor 5 (transition I-II). It then stays constant until around $4.1 \mathrm{~V}(\mathrm{t}=20,000 \mathrm{~s})$ when the optical signal is temporarily lost, likely due to gas evolution (region III in c); bubbles flowing from the battery into the hollow-core fibre are also observed via their side-scattered light (see Supplementary Movie 1). During the 
voltage hold no further bubbles were observed, as evidenced by the full recovery of the optical signal intensity. Subsequently, during discharge at around $4.1 \mathrm{~V}$, the EC intensity decreases sharply again (transition IV-V). The VC C=C band, on the other hand, appears to increase slightly during the formation cycle (grey curve in Fig. 5d). The results appear to indicate that additional VC is generated within the battery during the cycle. This result was somewhat surprising, as while VC generation has been proposed as a result of electrolyte oxidation, ${ }^{20}$ loss of VC to form the SEI during the formation SEI is also expected.
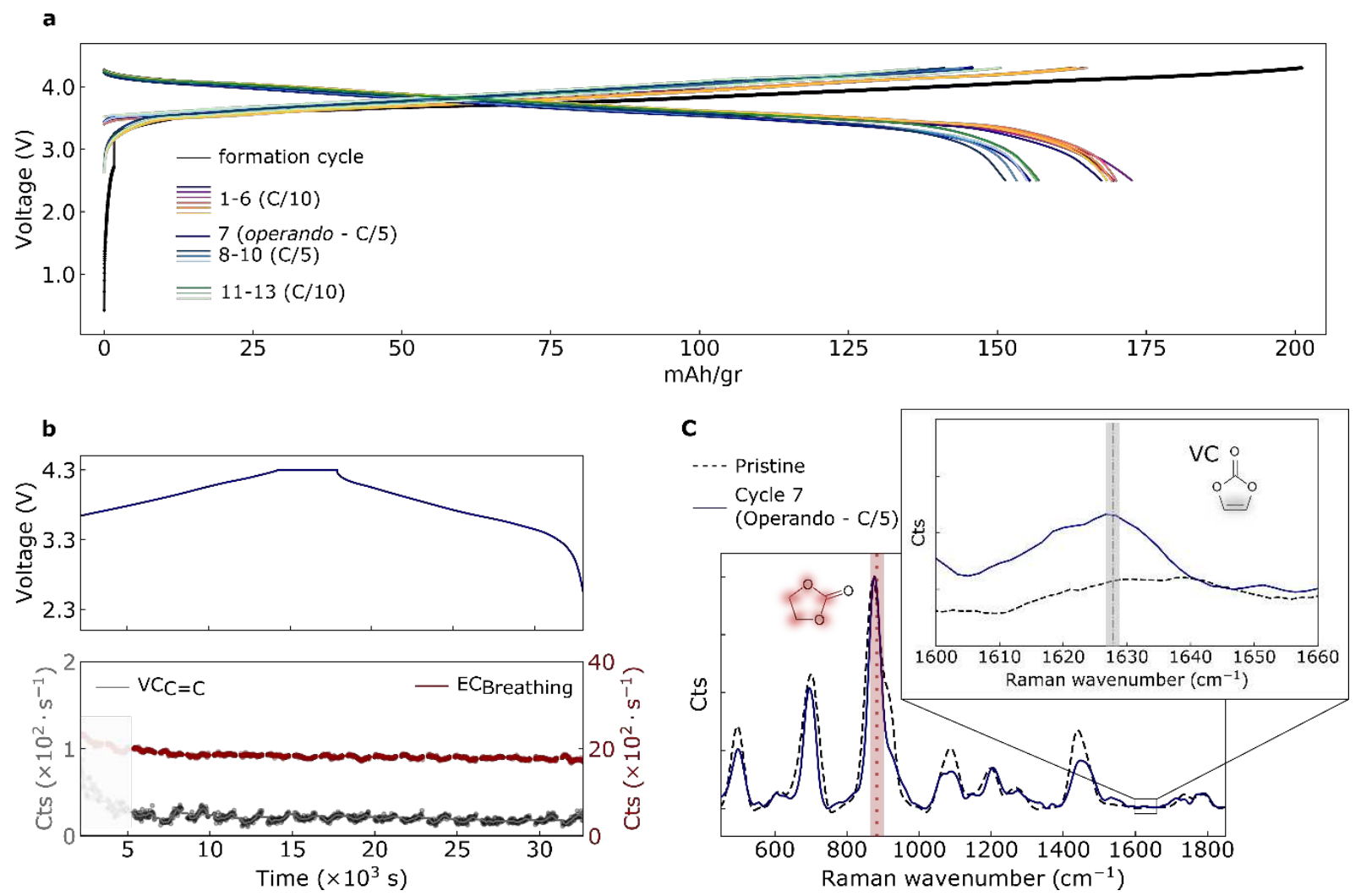

Fig. 6 | Long-term cycling and Raman analysis. a, Charge/Discharge voltage profiles of a Li-ion pouch cell (anode: graphite, cathode: NMC811, electrolyte: LP57 without VC additive) cycled at C/10 and C/5 rates. b, Operando analysis and time evolution of EC (red dashed line) and VC (grey dash-dotted line) Raman band intensities during cycle 7. Note that only Raman data for $\mathrm{t}>5 \times 10^{3} \mathrm{~s}$ are shown, after which the fluid sampling has stabilised after reconnecting the cell to the HC-fibre. The small periodic modulation in intensity is related to the fluidic sampling interval. c, Comparison between Raman spectra of pristine (not cycled) LP57 electrolyte (dashed line) and electrolyte extracted at the end of cycle 7 . The inset in c shows the VC C=C Raman band detected in cycled electrolyte. 
Multi-cycle measurements. The change in VC concentration during cycling and the ability of our analytical approach to study electrolyte chemical composition over multiple cycles were then investigated. To test whether VC is generated in the cell, a new pouch cell was initially filled with LP57 electrolyte without VC additive. In these experiments, a silica glass capillary (150 $\mu \mathrm{m}$ outer diameter, 75 $\mu \mathrm{m}$ inner diameter) was inserted between the graphite and NMC811 electrodes (see Supplementary Fig. 7). During Raman measurements, the capillary was connected to a HC-fibre using low-dead-volume microfluidic fittings. This flexible approach allows the electrolyte chemistry of multiple cells to be analysed using a single microfluidic pump and Raman apparatus and will be useful for long-term, multiple-cell cycling studies.

The cell is electrochemically charged and discharged and voltage profile graphs are taken during multiple cycles (a formation cycle followed by 6 cycles at C/10, 4 cycles at C/5 and finally 3 cycles at C/10, see Fig. 6a). The cell retains ca. $90 \%$ of its discharge capacity after 13 cycles (compared to the first-cycle discharge), demonstrating that the insertion of the glass micro-capillary does not affect the electrochemical performance of the cell substantially. During cycle 7, the cell was connected to the HC-fibre and an operando Raman measurement is performed (Fig. 6b, top shows the charge and discharge voltage profile). Interestingly, the EC breathing mode remains largely stable throughout the cycle (Fig. $\mathbf{6 b}$ bottom, Raman bands intensity), in stark contrast with the large fluctuations observed during formation-cycle measurements (Fig. 5). Furthermore, no bubble formation is observed during the $7^{\text {th }}$ cycle. Finally, a nonzero VC C $=\mathrm{C}$ mode intensity is observed, clearly indicating that VC has been generated during cycling. The formation of VC by electrolyte oxidation becomes more apparent when the spectra at the end of cycle 7 are compared to those of the pristine electrolyte (Fig $6 \mathrm{c}$ ). The data clearly confirm that the large EC fluctuations, VC formation, and bubbles observed during the formation-cycle measurements (Fig. 5) are indeed related to electrochemical processes during the first electrochemical cycle. 


\section{Discussion}

The operando spectroscopy gives access to a large number of Raman signatures not previously accessible in full cells. We thus provide tentative explanations to highlight which processes can be studied using such HC fibre-based operational techniques.

$\mathrm{Li}^{+}$solvation: The increase of the $E C \mathrm{C}=\mathrm{O}$ relative to the $\mathrm{EMC} \mathrm{C}=\mathrm{O}$ Raman mode measured in regions $\mathrm{II}$ IV (Fig. $\mathbf{d 5 d}$ ) is likely related to the effect of $\mathrm{Li}^{+}$solvation. The shape of the spectra seems to indicate preferential $\mathrm{Li}^{+}$solvation at the $\mathrm{EC} \mathrm{C}=\mathrm{O}$ with respect to $\mathrm{EMC} \mathrm{C}=\mathrm{O}^{64}$ (also seen in our control experiments (see Supplementary Fig. 5)), which may also contribute to the increase in EC-breathing mode intensity with respect to the initial value observed in Fig. 4. The EC/EMC C=O band ratio (Fig. $5 \mathbf{c}$ ) reduces after the voltage hold at maximum charge a phenomenon that requires further studies to understand but may be related to different concentration gradients that build up in the cell on charge vs. discharge or effects due to bubble formation. We note, however, that the observed increase in carbonate Raman bands with cell voltage are similar to surface-sensitive IR absorption changes from in-situ FT-IR data in NMC811 half-cells in Ref. [9], which attributes this to electrolyte oxidation at the Ni-rich electrode surface. Our operando Raman data, however, detects these increases away from the surface, in the bulk electrolyte.

VC-concentration changes: the increase in the VC band in Fig. $\mathbf{5 d}$, and in particular the occurrence of a VC band in a cell without initial VC (Fig $\mathbf{6 c}$ ) are consistent with VC formation via oxidation of EC. The jump in VC signal after the potentiostatic hold (Fig. 5d) may also be related to lattice oxygen release from NMC in the form of reactive singlet oxygen, which causes the chemical oxidation of EC into VC. ${ }^{20}$ Interestingly, the $\mathrm{Li}^{+}$solvation structure in EC and EMC solvents affect the $\mathrm{Li}^{+}$diffusion coefficient in the electrolyte ${ }^{58}$ with implications of this mechanism as a diagnostic tool of battery operation.

Bubble formation: The temporary loss of optical signal during the final stage of the charging cycle is confirmed to be due to the formation of bubbles. Since they are observed in different formation-cycle Page 16 of 29 
experiments (see Supplementary Fig. 6), but are largely absent during later cycles (Fig. 6), these are likely related to gas generation in EEl formation reactions during the formation cycle $\left(\mathrm{CO}, \mathrm{CO}_{2}, \mathrm{C}_{2} \mathrm{H}_{4}\right) \cdot{ }^{65}$ In the current configuration, the detection of such bubbles within the central compartment will be delayed, as bubbles need to diffuse though the separator, and coalesce to become detected in the HC-fibre. We note that our capillary set up, in principle, provides a straightforward method to couple the pouch cell with a mass-spectrometer for gas analysis.

EC-Raman band: The EC breathing mode shows a significant evolution in intensity during the formation cycle (Fig. 5d), consistent with the trend in ratio of EC/EMC C=O stretch (Fig 4c). We identify possible reasons for this large change in intensity. First, it is well-known that the $\mathrm{Li}^{+}$concentration and battery state of charge can affect spectral features of solvent Raman bands. ${ }^{57,62,63,66}$ For example, FT-IR studies in a halfcell configuration have suggested that the peak position and intensity of the EC C=O Raman mode is affected by the $\mathrm{Li}^{+}$concentration and that EC undergoes a progressive de-hydrogenation correlated with the cathodic potential. ${ }^{9}$ At the same time, we observe a 5-fold increase in the EC breathing mode, which cannot be explained by variations in $\mathrm{Li}^{+}$concentration alone: our calibration data (Supplementary Fig. 6) demonstrates at most a two-fold increase for a change in Li concentration from 0.5 to $1 \mathrm{M}$. A further factor that could contribute to the observed trend is the modification in the solvation structure of $\mathrm{Li}^{+}-\mathrm{O}=\mathrm{C}$ of EC which can change the intensity of the EC breathing mode spectral band $\left(880-915 \mathrm{~cm}^{-1}\right) \cdot{ }^{57,62}$ We note that the Raman data in cycle 7 (Fig. 6b) does not show significant EC-band fluctuations, supporting the hypothesis that the effects are related to the formation cycle. Second, changes in $\mathrm{Li}^{+}$solvation will likely increase the refractive index of the electrolyte by typically $0.1 \%$ per $\mathrm{Li}^{+}$molar concentration, as was demonstrated with different salts and salt concentations. ${ }^{67,68}$ This changes the interference conditions in the fibre and may affect the amount of Raman pump light propagating along the hollow-core fibre. ${ }^{39}$ 


\section{Conclusions}

Hollow-core fibre sensors, embedded in working Li-ion batteries, can measure background-free Raman spectra of electrolytes during electrochemical cycling. The novel sensors were used here to monitor a fullcell Li-ion battery comprising of a commercially-relevant high energy Ni-rich layered oxide cathode (NMC811) and a graphite anode. As a proof-of-principle, electrolyte Raman spectra were continuously acquired during the formation cycle, during which (among other things) the solid electrode interphase (SEI) is created. We have observed significant changes in lithium solvation with carbonate solvents during charges, and are able to track changes in VC concentration. Multi-cycle measurements without initial VC additive confirmed that the EC fluctuations and VC generation occur in the formation cycle.

Our results demonstrate that hollow-core fibre spectroscopy allows for studies of how (electro)chemical degradation of electrolytes affects the lithium solvation dynamics. Operando electrolyte monitoring can facilitate the study of complex chemical pathways and cross-talk between chemical species in a real-world battery. A key example is the observation of an increasing VC signal beyond its initial concentration, suggesting that this is generated through EC oxidation during cycling, as was proposed by Ref [20], and that the rate of VC generation on the cathode is greater than its consumption at the anode.

\section{Methods}

Battery assembly and cycling. Full-cells were assembled into a pouch cell in a dry room $\left(\mathrm{H}_{2} \mathrm{O}<0.1 \%\right)$. Pouch components (foil, current collector tabs, PE polymer separators and sealant tape) were purchased from MTI. Graphite anode and $\mathrm{LiNi}_{0.8} \mathrm{CO}_{0.1} \mathrm{Mn}_{0.1} \mathrm{O}_{2}$ (NMC811) cathode sheets were kindly provided by the Argonne National Laboratory Cell Analysis, Modelling, and Prototyping (CAMP) facility. Graphite electrodes consisted of 91.83 wt.\% Hitachi MagE3 artificial graphite, 2 wt.\% Timcal C45 conductive carbon, 6 wt.\% Kureha 9300 polyvinylidene difluoride (PVDF) binder, and 0.17 wt.\% oxalic acid printed onto 10 $\mu \mathrm{m}$ thick copper foil. NMC811 electrodes were made up of 90 wt.\% Targray NMC 811, 5 wt.\% Solvay 5130 
PVDF binder, and 5 wt.\% Timcal C45 conductive carbon on 20 um thick aluminium foil. Pre-cut electrodes (14 $\mathrm{mm}$ dia. NMC cathode and $15 \mathrm{~mm}$ dia. graphite anode) were dried in a vacuum oven $\left(120^{\circ} \mathrm{C}\right.$ for $>12$ h) and stored in a glove box $\left(<0.5 \mathrm{ppm} \mathrm{H}_{2} \mathrm{O}\right.$ and $\left.\mathrm{O}_{2}\right)$ prior to use. Graphite and NMC active mass loading were $5.83 \mathrm{mg}_{\mathrm{Gr}} \mathrm{cm}^{-2}$ and $8.21 \mathrm{mg}_{\mathrm{NMC}} \mathrm{cm}^{-2}$, respectively. Battery electrolytes, solvents and additives (LP57, EC:EMC 3:7) were purchased from SoulBrain, VC was purchased from Solvionic. The hollow-core fibre was placed between electrodes and two layers of polymer separator to prevent contact with the electrode surfaces (see Supplementary Fig. 4). Cells were cycled with an Autolab PGSTAT204 (Metrohm) potentiostat at a C-rate of $\mathrm{C} / 10$ (based on $185 \mathrm{mAh} \mathrm{g}^{-1} \mathrm{NMC}$ ) with a constant current (CC) charge to $4.3 \mathrm{~V}$, constant voltage (CV) hold step for $1 \mathrm{~h}$, and CC discharge to $3.5 \mathrm{~V}$.

Hollow-core fibre design. The fibre used is a simplified hollow-core photonic crystal fibre fabricated using a stack and draw process. ${ }^{31}$ The fibre preform was created by positioning six thin-walled silica glass capillaries in the corners of a larger tube with a hexagonal hole, which is first drawn into several smaller secondary preforms ("canes"), and then drawn to fibre. Detailed Scanning Electron Microscopy (SEM) analysis of the hollow-core fibre and its photonic structures can be found in Supplementary Fig. 1. The outer diameter of the fibre was $174 \mu \mathrm{m}$, the six inner capillaries have inner diameters between 16-18 $\mu \mathrm{m}$. The resulting diameter of the hollow core (measured from capillary to capillary) is $36 \mu \mathrm{m}$. The wall thickness $t$ of the internal capillaries is between $\sim 410$ and $440 \mathrm{~nm}$.

The guidance properties of this type of microstructured fibre are predicted by the anti-resonant reflection model ${ }^{39}$, which calculates resonant wavelengths (for which light can resonantly leak out of the fibre) and antiresonant wavelengths (for which the cladding layer acts as a mirror and light is guided along the fibre). For a fibre filled with a typical electrolyte mixture (refractive index at $785 \mathrm{~nm} n_{1} \sim 1.39$ ) and a glass refractive index of $n_{2}=1.455$, we can predict the first anti resonant wavelength to be $\lambda_{A R}=$ $4 t \sqrt{n_{2}^{2}-n_{1}^{2}}=731 \mathrm{~nm}$, very close to the wavelength of the Raman laser. The transmission of light coupled Page 19 of 29 
into the electrolyte-filled fibre was measured to be of order $15-20 \%$. We note that the fibre guidance properties in this type of fibre are robust against changes in electrolyte refractive index (see Supplementary Fig. 2), which is evidenced by the Raman measurements in a range of electrolyte mixtures with different refractive indices in Fig $\mathbf{2 b}$.

Microfluidic pressure cell. To reduce the response time of the system when exchanging the liquid in the hollow fibre core, the compliance and dead volume of the fluidic connections were minimized. The proximate end of the fibre is connected to a specially designed low-volume stainless-steel cell, covered by a sapphire optical access window (Edmund Optics), resulting in an internal volume of $230 \mathrm{~nL}$. The cell is connected to an automated syringe pump (New Era Pump) actuating a $50 \mu \mathrm{L}$ Hamilton syringe. The response time of the low dead volume microfluidic circuit was estimated to be 1-2 min, and is currently limited by the internal volume of the syringe. ${ }^{69}$ The geometry of the fibre embedded in the pouch cell is detailed in Supplementary Figures 4 and 7. To assemble the microfluidic sampling line we used Polyether ether ketone (PEEK) parts and Zero-Dead-Volume (ZDV) fittings (IDEX Health \& Science, LLC, USA).

Raman collection. Spontaneous Raman measurements were recorded on a custom-built Pythonautomated Raman setup. Excitation and collection were through a 10x 0.3 NA Olympus Plan Fluorite objective. Spectra were recorded by a Pixis 1024-element cooled CCD camera coupled to an Acton 330i Spectrometer (Teledyne Princeton Instruments, USA). To enable simultaneous monitoring of multiple different Raman bands, a grating with a period of 300 grooves per $\mathrm{mm}$ was combined with a $25 \mu \mathrm{m}$ entrance slit, enabling detection in a broad spectral window $\left(644-2344 \mathrm{~cm}^{-1}\right)$ with a resolution of $\sim 40 \mathrm{~cm}^{-}$ 1. We note that the resolution can be improved to $10 \mathrm{~cm}^{-1}$ by using a 1200 lines $/ \mathrm{mm}$ grating, at the cost of a decreased spectral range. Automated scans and syringe pump control were performed by a Python interface code. 


\section{References}

1. Jung, R., Metzger, M., Maglia, F., Stinner, C. \& Gasteiger, H. A. Chemical versus Electrochemical Electrolyte Oxidation on NMC111, NMC622, NMC811, LNMO, and Conductive Carbon. J. Phys. Chem. Lett. 8, 4820-4825 (2017).

2. Park, K.-J. et al. Degradation Mechanism of Ni-Enriched NCA Cathode for Lithium Batteries: Are Microcracks Really Critical? ACS Energy Lett. 4, 1394-1400 (2019).

3. Lin, Q. et al. Ni-Li anti-site defect induced intragranular cracking in Ni-rich layer-structured cathode. Nano Energy 76, 105021 (2020).

4. Gilbert, J. A., Shkrob, I. A. \& Abraham, D. P. Transition Metal Dissolution, Ion Migration, Electrocatalytic Reduction and Capacity Loss in Lithium-Ion Full Cells. J. Electrochem. Soc. 164, A389-A399 (2017).

5. Jung, R., Metzger, M., Maglia, F., Stinner, C. \& Gasteiger, H. A. Oxygen Release and Its Effect on the Cycling Stability of $\mathrm{LiNi}_{x} \mathrm{Mn}_{y} \mathrm{Co}_{z} \mathrm{O}_{2}$ (NMC) Cathode Materials for Li-Ion Batteries. J. Electrochem. Soc. 164, A1361-A1377 (2017).

6. Streich, D. et al. Operando Monitoring of Early Ni-mediated Surface Reconstruction in Layered Lithiated Ni-Co-Mn Oxides. J. Phys. Chem. C 121, 13481-13486 (2017).

7. Lin, F. et al. Profiling the nanoscale gradient in stoichiometric layered cathode particles for lithiumion batteries. Energy Environ. Sci. 7, 3077-3085 (2014).

8. Yu, Y. et al. Coupled LiPF 6 Decomposition and Carbonate Dehydrogenation Enhanced by Highly Covalent Metal Oxides in High-Energy Li-Ion Batteries. J. Phys. Chem. C 122, 27368-27382 (2018). 
9. Zhang, Y. et al. Revealing electrolyte oxidation via carbonate dehydrogenation on Ni-based oxides in Li-ion batteries by in situ Fourier transform infrared spectroscopy. Energy Environ. Sci. 13, 183-199 (2020).

10. Østergaard, T. M. et al. Oxidation of Ethylene Carbonate on Li Metal Oxide Surfaces. J. Phys. Chem. C $122,10442-10449$ (2018).

11. Giordano, L. et al. Chemical Reactivity Descriptor for the Oxide-Electrolyte Interface in Li-Ion Batteries. J. Phys. Chem. Lett. 8, 3881-3887 (2017).

12. Jung, R. et al. Nickel, Manganese, and Cobalt Dissolution from Ni-Rich NMC and Their Effects on NMC622-Graphite Cells. J. Electrochem. Soc. 166, A378 (2019).

13. Soto, F. A., Ma, Y., Martinez de la Hoz, J. M., Seminario, J. M. \& Balbuena, P. B. Formation and Growth Mechanisms of Solid-Electrolyte Interphase Layers in Rechargeable Batteries. Chem. Mater. 27, 7990-8000 (2015).

14. Bloom, l. et al. Differential voltage analyses of high-power lithium-ion cells. 4. Cells containing NMC. J. Power Sources 195, 877-882 (2010).

15. Harlow, J. E. et al. A Wide Range of Testing Results on an Excellent Lithium-Ion Cell Chemistry to be used as Benchmarks for New Battery Technologies. J. Electrochem. Soc. 166, A3031-A3044 (2019).

16. Lin, F. et al. Surface reconstruction and chemical evolution of stoichiometric layered cathode materials for lithium-ion batteries. Nat. Commun. 5, 3529 (2014).

17. Xiao, P., Shi, T., Huang, W. \& Ceder, G. Understanding Surface Densified Phases in Ni-Rich Layered Compounds. ACS Energy Lett. 4, 811-818 (2019). 
18. Streich, D. et al. Online Electrochemical Mass Spectrometry of High Energy Lithium Nickel Cobalt Manganese Oxide/Graphite Half- and Full-Cells with Ethylene Carbonate and Fluoroethylene Carbonate Based Electrolytes. J. Electrochem. Soc. 163, A964 (2016).

19. Sealy, C. Oxygen to blame for Li-ion battery breakdown. Mater. Today 21, 806 (2018).

20. Freiberg, A. T. S., Roos, M. K., Wandt, J., de Vivie-Riedle, R. \& Gasteiger, H. A. Singlet Oxygen Reactivity with Carbonate Solvents Used for Li-Ion Battery Electrolytes. J. Phys. Chem. A 122, 88288839 (2018).

21. Aurbach, D. et al. On the use of vinylene carbonate (VC) as an additive to electrolyte solutions for Liion batteries. Electrochimica Acta 47, 1423-1439 (2002).

22. Grey, C. P. \& Tarascon, J. M. Sustainability and in situ monitoring in battery development. Nat. Mater. 16, 45-56 (2017).

23. Cabo-Fernandez, L. et al. Kerr gated Raman spectroscopy of LiPF 6 salt and LiPF 6 -based organic carbonate electrolyte for Li-ion batteries. Phys. Chem. Chem. Phys. 21, 23833-23842 (2019).

24. Sole, C., Drewett, N. E. \& Hardwick, L. J. In situ Raman study of lithium-ion intercalation into microcrystalline graphite. Faraday Discuss. 172, 223-237 (2014).

25. Song, H.-Y., Fukutsuka, T., Miyazaki, K. \& Abe, T. In situ Raman investigation of electrolyte solutions in the vicinity of graphite negative electrodes. Phys. Chem. Chem. Phys. 18, 27486-27492 (2016).

26. Cheng, Q. et al. Operando and three-dimensional visualization of anion depletion and lithium growth by stimulated Raman scattering microscopy. Nat. Commun. 9, (2018).

27. Sommer, L. W. et al. Fast and slow ion diffusion processes in lithium ion pouch cells during cycling observed with fiber optic strain sensors. J. Power Sources 296, 46-52 (2015). 
28. Amietszajew, T., McTurk, E., Fleming, J. \& Bhagat, R. Understanding the limits of rapid charging using instrumented commercial 18650 high-energy Li-ion cells. Electrochimica Acta 263, 346-352 (2018).

29. Yamanaka, T. et al. Ultrafine Fiber Raman Probe with High Spatial Resolution and Fluorescence Noise Reduction. J. Phys. Chem. C 120, 2585-2591 (2016).

30. Yamanaka, T. et al. In situ diagnosis of the electrolyte solution in a laminate lithium ion battery by using ultrafine multi-probe Raman spectroscopy. J. Power Sources 359, 435-440 (2017).

31. Russell, P. Photonic Crystal Fibers. Science 299, 358 (2003).

32. Benabid, F., Knight, J. C., Antonopoulos, G. \& Russell, P. S. J. Stimulated Raman Scattering in Hydrogen-Filled Hollow-Core Photonic Crystal Fiber. Science 298, 399-402 (2002).

33. Russell, P. S. J., Hölzer, P., Chang, W., Abdolvand, A. \& Travers, J. C. Hollow-core photonic crystal fibres for gas-based nonlinear optics. Nat. Photonics 8, 278-286 (2014).

34. M. Cubillas, A. et al. Photonic crystal fibres for chemical sensing and photochemistry. Chem. Soc. Rev. 42, 8629-8648 (2013).

35. Ghenuche, P. et al. Kagome hollow-core photonic crystal fiber probe for Raman spectroscopy. Opt. Lett. 37, 4371-4373 (2012).

36. Yerolatsitis, S. et al. Ultra-low background Raman sensing using a negative-curvature fibre and no distal optics. J. Biophotonics 12, (2019).

37. Konorov, S. O., Addison, C. J., Schulze, H. G., Turner, R. F. B. \& Blades, M. W. Hollow-core photonic crystal fiber-optic probes for Raman spectroscopy. Opt. Lett. 31, 1911-1913 (2006). 
38. Yan, D., Popp, J., Pletz, M. W. \& Frosch, T. Highly Sensitive Broadband Raman Sensing of Antibiotics in Step-Index Hollow-Core Photonic Crystal Fibers. ACS Photonics 4, 138-145 (2017).

39. Litchinitser, N. M., Abeeluck, A. K., Headley, C. \& Eggleton, B. J. Antiresonant reflecting photonic crystal optical waveguides. Opt. Lett. 27, 1592-1594 (2002).

40. Poletti, F. Nested antiresonant nodeless hollow core fiber. Opt. Express 22, 23807-23828 (2014).

41. Frosz, M. H., Roth, P., Günendi, M. C. \& Russell, P. St. J. Analytical formulation for the bend loss in single-ring hollow-core photonic crystal fibers. Photonics Res. 5, 88 (2017).

42. Pryamikov, A. D. et al. Demonstration of a waveguide regime for a silica hollow - core microstructured optical fiber with a negative curvature of the core boundary in the spectral region \&gt; 3.5 m. Opt. Express 19, 1441-1448 (2011).

43. Yu, F., Wadsworth, W. J. \& Knight, J. C. Low loss silica hollow core fibers for 3-4 $\mu \mathrm{m}$ spectral region. Opt. Express 20, 11153-11158 (2012).

44. Pritzl, D., Solchenbach, S., Wetjen, M. \& Gasteiger, H. A. Analysis of Vinylene Carbonate (VC) as Additive in Graphite/LiNi $0.5 \mathrm{Mn}_{1.5} \mathrm{O}_{4}$ Cells. J. Electrochem. Soc. 164, A2625-A2635 (2017).

45. Goodenough, J. B. \& Kim, Y. Challenges for Rechargeable Li Batteries. Chem. Mater. 22, 587-603 (2010).

46. Peled, E. Film forming reaction at the lithium/electrolyte interface. J. Power Sources 9, 253-266 (1983).

47. Hayes, J. R. et al. Antiresonant Hollow Core Fiber with Octave Spanning Bandwidth for Short Haul Data Communications. in Optical Fiber Communication Conference Postdeadline Papers Th5A.3 (Optical Society of America, 2016). doi:10.1364/OFC.2016.Th5A.3. 
48. Cubillas, A. M. et al. Photonic crystal fibres for chemical sensing and photochemistry. Chem. Soc. Rev. 42, 8629-8648 (2013).

49. Han, S.-D. et al. Solvate Structures and Computational/Spectroscopic Characterization of LiPF 6 Electrolytes. J. Phys. Chem. C 119, 8492-8500 (2015).

50. Nakamoto, K. Infrared and Raman Spectra of Inorganic and Coordination Compounds. in Handbook of Vibrational Spectroscopy (American Cancer Society, 2006). doi:10.1002/0470027320.s4104.

51. Cui, W., Lansac, Y., Lee, H., Hong, S.-T. \& Jang, Y. H. Lithium ion solvation by ethylene carbonates in lithium-ion battery electrolytes, revisited by density functional theory with the hybrid solvation model and free energy correction in solution. Phys. Chem. Chem. Phys. 18, 23607-23612 (2016).

52. Aroca, R., Nazri, M., Nazri, G. A., Camargo, A. J. \& Trsic, M. Vibrational Spectra and Ion-Pair Properties of Lithium Hexafluorophosphate in Ethylene Carbonate Based Mixed-Solvent Systems for Lithium Batteries. 14.

53. Dorris, K. L., Boggs, J. E., Danti, A. \& Altpeter, L. L. Infrared and Raman Spectra of Vinylene Carbonate. J. Chem. Phys. 46, 1191-1193 (1967).

54. Xu, S. et al. Ab Initio Modeling of Electrolyte Molecule Ethylene Carbonate Decomposition Reaction on Li(Ni,Mn,Co)O2 Cathode Surface. ACS Appl. Mater. Interfaces 9, 20545-20553 (2017).

55. Xu, K., Lam, Y., Zhang, S. S., Jow, T. R. \& Curtis, T. B. Solvation Sheath of Li+ in Nonaqueous Electrolytes and Its Implication of Graphite/Electrolyte Interface Chemistry. J. Phys. Chem. C 111, 7411-7421 (2007).

56. von Wald Cresce, A., Borodin, O. \& Xu, K. Correlating Li+ Solvation Sheath Structure with Interphasial Chemistry on Graphite. J. Phys. Chem. C 116, 26111-26117 (2012). 
57. Giorgini, M. G., Futamatagawa, K., Torii, H., Musso, M. \& Cerini, S. Solvation Structure around the Li + Ion in Mixed Cyclic/Linear Carbonate Solutions Unveiled by the Raman Noncoincidence Effect. J. Phys. Chem. Lett. 6, 3296-3302 (2015).

58. Ong, M. T. et al. Lithium Ion Solvation and Diffusion in Bulk Organic Electrolytes from First-Principles and Classical Reactive Molecular Dynamics. J. Phys. Chem. B 119, 1535-1545 (2015).

59. Fulfer, K. D. \& Kuroda, D. G. A comparison of the solvation structure and dynamics of the lithium ion in linear organic carbonates with different alkyl chain lengths. Phys. Chem. Chem. Phys. 19, 2514025150 (2017).

60. Lim, J. et al. Two-Dimensional Infrared Spectroscopy and Molecular Dynamics Simulation Studies of Nonaqueous Lithium Ion Battery Electrolytes. J. Phys. Chem. B 123, 6651-6663 (2019).

61. Liang, C., Kwak, K. \& Cho, M. Revealing the Solvation Structure and Dynamics of Carbonate Electrolytes in Lithium-Ion Batteries by Two-Dimensional Infrared Spectrum Modeling. J. Phys. Chem. Lett. 8, 5779-5784 (2017).

62. Klassen, B., Aroca, R., Nazri, M. \& Nazri, G. A. Raman Spectra and Transport Properties of Lithium Perchlorate in Ethylene Carbonate Based Binary Solvent Systems for Lithium Batteries. J. Phys. Chem. B 102, 4795-4801 (1998).

63. Cresce, A. V. et al. Solvation behavior of carbonate-based electrolytes in sodium ion batteries. Phys. Chem. Chem. Phys. 19, 574-586 (2017).

64. Borodin, O. et al. Competitive lithium solvation of linear and cyclic carbonates from quantum chemistry. Phys. Chem. Chem. Phys. 18, 164-175 (2016). 
65. Schwenke, K. U., Solchenbach, S., Demeaux, J., Lucht, B. L. \& Gasteiger, H. A. The Impact of $\mathrm{CO}_{2}$ Evolved from VC and FEC during Formation of Graphite Anodes in Lithium-lon Batteries. J. Electrochem. Soc. 166, A2035-A2047 (2019).

66. Schroder, K. W. et al. Effects of Solute-Solvent Hydrogen Bonding on Nonaqueous Electrolyte Structure. J. Phys. Chem. Lett. 6, 2888-2891 (2015).

67. Tan, C.-Y. \& Huang, Y.-X. Dependence of Refractive Index on Concentration and Temperature in Electrolyte Solution, Polar Solution, Nonpolar Solution, and Protein Solution. J. Chem. Eng. Data 60, 2827-2833 (2015).

68. Nedjalkov, A. et al. Refractive Index Measurement of Lithium Ion Battery Electrolyte with Etched Surface Cladding Waveguide Bragg Gratings and Cell Electrode State Monitoring by Optical Strain Sensors. Batteries 5, 30 (2019).

69. Microfluidics/Hydraulic resistance and capacity - Wikibooks, open books for an open world. https://en.wikibooks.org/wiki/Microfluidics/Hydraulic_resistance_and_capacity. 


\section{Acknowledgements}

This work is supported by the Faraday Institution under grant no. FIRG001 and the Winton Programme for the Physics of Sustainability. The authors are grateful to A. Jansen, S. Trask, B.J. Polzin, and A.R. Dunlop at the U.S. Department of Energy's CAMP (Cell Analysis, Modeling, and Prototyping) Facility, Argonne National Laboratory, for producing and supplying the electrodes in this work.

\section{Author contributions}

T.G.E., J.J.B., C.P.G., and E.M. conceived the concept. E.M., T.G.E., and J.J.B. designed the optical setup, and E.M. conducted the optical experiments, aided by I.M.. Battery samples were prepared by E.M. and W.M.D.. The hollow-core fibres were designed and fabricated by M.H.F.. All authors analysed the data and co-wrote the paper.

\section{Competing interests}

E.M., J.J.B., C.P.G., and T.G.E. are applicants and inventors on a patent on the fibre-optic sensing apparatus and method discussed in the manuscript, patent application number: P/80651.GB01/SG (pending). 


\section{Supplementary Files}

This is a list of supplementary files associated with this preprint. Click to download.

- MieleSupplementaryinformation.docx 